\title{
SINGLE-STAGE EXTENSIVE REPLACEMENT OF THE THORACIC AORTA: THE ARCH-FIRST TECHNIQUE
}

Chris K. Rokkas, MD

Nicholas T. Kouchoukos, MD
Background: Single-stage extensive replacement of the thoracic aorta usually involves a period of circulatory arrest with performance of the graft-to-lower descending thoracic aorta anastomosis before performing the anastomosis to the arch vessels. To minimize the period of brain ischemia and reduce the potential for neurologic injury, we developed an alternative technique. Methods: In 6 patients with extensive aneurysms involving the entire thoracic aorta, exposure was obtained via a bilateral thoracotomy in the anterior fourth intercostal space with transverse sternotomy. A $\mathbf{1 0}-\mathbf{m m}$ graft was anastomosed to the aortic graft, opposite the site of the planned anastomosis to the arch vessels. During a single period of circulatory arrest (34-46 minutes), the aortic graft was attached to a cuff of aorta containing the arch vessels. The graft was then clamped on either side, and the arch was perfused with cold blood for 20 to 36 minutes. After the distal aortic anastomosis was completed, antegrade perfusion was established via the $10-\mathrm{mm}$ graft. The proximal aortic anastomosis was performed last. Results: No patient sustained a permanent neurologic deficit. All 6 patients were discharged from the hospital. Conclusions: The "arch-first" technique, combined with a bilateral transverse thoracotomy, allows expeditious replacement of the thoracic aorta with an acceptable interval of hypothermic circulatory arrest and minimizes the risk of retrograde atheroembolism by establishing antegrade perfusion. (J Thorac Cardiovasc Surg 1999; 117:99-105)
$A^{n}$ neurysmal disease that involves the ascending aorta, arch, and descending aorta is usually approached in staged operations. ${ }^{1-3}$ In certain situations (extensive involvement of the arch, presence of symptoms, impending rupture) a single-stage approach may be preferred. ${ }^{4-6}$ Traditionally, single-stage replacement of the thoracic aorta involves a period of circulatory arrest and the performance of the graft-to-lower descending thoracic aorta anastomosis before the anastomosis to the arch vessels is performed. ${ }^{7,8}$ Perfusion is then reestablished in a retrograde fashion via a femoral arterial cannula, and the ascending aortic anastomosis is completed.

From the Heart Center, Missouri Baptist Medical Center, St Louis, Mo. Received for publication May 28, 1998; revisions requested July 10, 1998; revisions received Aug 6, 1998; accepted for publication Aug 11, 1998.

Address for reprints: Nicholas T. Kouchoukos, MD, 3009 N Ballas Rd, Suite 266C, St Louis, MO 63131.

Copyright (C) 1999 by Mosby, Inc.

$0022-5223 / 99 \$ 8.00+0 \quad \mathbf{1 2 / 1 / 9 3 7 7 9}$
Despite advances in anesthetic management and cardiopulmonary perfusion, brain injury remains an important source of morbidity and mortality in operations on the thoracic aorta. In operations requiring the use of profound hypothermia and circulatory arrest, perioperative stroke with a focal neurologic deficit is related to the presence of concurrent distal aortic disease and to the duration of circulatory arrest. ${ }^{9}$ Temporary neurologic dysfunction is related to the cerebral ischemia time although permanent neurologic dysfunction is the result of embolic strokes. ${ }^{10}$ To minimize the time of circulatory arrest and to reduce the duration of retrograde aortic perfusion, we developed a technique that involves anastomosis of the aortic graft to the arch vessels first and hypothermic perfusion of these vessels while reconstruction of the descending thoracic aorta is performed. We report our experience with 6 consecutive patients in whom the arch-first technique in combination with a bilateral anterior thoracotomy and transverse sternotomy was used for single-stage, extensive replacement of the thoracic aorta. 
Table I. Demographic data, clinical pathologic findings, surgical procedures, and outcome

\begin{tabular}{|c|c|c|c|c|}
\hline Patient & $\begin{array}{l}\text { Age } \\
(y)\end{array}$ & Sex & Previous operation & Type of disease \\
\hline 1 & 74 & M & None & Chronic type B dissection \\
\hline 2 & 72 & M & $\begin{array}{l}\text { Acute type A dissection repair: } \\
\text { tube graft, AVR }(10 \mathrm{y})\end{array}$ & Chronic type A dissection \\
\hline 3 & 69 & M & $\begin{array}{l}\text { Acute type A dissection repair: } \\
\text { tube graft, AVR (11 y) }\end{array}$ & Chronic type A dissection \\
\hline 4 & 60 & $\mathrm{~F}$ & None & Degenerative aneurysm \\
\hline 5 & 49 & M & $\begin{array}{l}\text { Acute type A dissection repair: } \\
\text { tube graft }(10 \mathrm{y})\end{array}$ & Chronic type A dissection \\
\hline 6 & 39 & M & $\begin{array}{l}\text { Acute type A dissection repair: } \\
\text { composite graft }(15 \mathrm{mo})\end{array}$ & Chronic type A dissection \\
\hline
\end{tabular}

$A A$, Ascending aorta; $A V R$, aortic valve replacement; $D T A$, descending thoracic aorta.

\section{Patients and methods}

Patients. From January 1996 to May 1998, 6 patients (mean age, 60.5 years; range, 39-74 years) underwent repair of the aortic arch and varying lengths of the ascending and descending thoracic aorta with the arch-first technique (Table I). Four of these patients, all men, had undergone previous operations for acute type $\mathrm{A}$ dissection (patients 2, 3, 5, and 6; mean interval, 8.1 years; range, 16 months-11 years). Patient 1 had a chronic type A dissecting aneurysm, and patient 4 had a degenerative fusiform aneurysm. None of the patients had Marfan's syndrome or other known microfibrillar disease. All patients had been treated for hypertension, and patients 2, 3, 4 , and 5 had moderate or severe chronic obstructive pulmonary disease. In patients 5 and 6 , the dissection involved the thoracoabdominal aorta, but without aneurysmal enlargement of the infradiaphragmatic segment. The indications for operation were progressive enlargement of the involved aortic segments documented by tomographic studies (all patients) and the presence of symptoms (patient 5, chest pain). All patients underwent preoperative cardiac catheterization and chest and abdominal computed tomographic scanning. Aortography was used selectively (Fig 1).

Operative technique. Hemodynamic monitoring includes bilateral radial artery cannulation for the monitoring of arterial pressure and placement of a pulmonary artery catheter. Electroencephalographic monitoring is used. Two lines for arterial perfusion are connected to the main arterial line of the pump-oxygenator to provide control of selective flow using an occluder and a flowmeter (HT 109; Transonic Systems, Inc, Ithaca, NY). Provisions are also made for retrograde brain perfusion. After endotracheal intubation with a doublelumen tube to permit deflation of the left lung, the patient is positioned on the operating table with the chest rotated 20 to 30 degrees from supine toward the right. The right arm is secured at the side, and the left arm is abducted on an armrest (Fig 2, inset).

Bilateral submammary anterior thoracotomy incisions are made with the left incision extending laterally to the midaxillary line and the right, to the anterior axillary line. The pleural spaces are entered; the internal thoracic vascular pedicles are ligated and divided bilaterally, and the sternum is divided transversely with an oscillating saw. Chest retractors are placed bilaterally. A common femoral artery is isolated through an oblique incision in the skin crease of the groin and is cannulated with a $20 \mathrm{~F}$ or $22 \mathrm{~F}$ cannula. The anterior mediastinal structures are exposed sufficiently to allow venous cannulation. Heparin is administered to achieve and maintain activated clotting time of greater than 500 seconds. Both venae cavae are cannulated separately through the right atrium, and cardiopulmonary bypass is established. A left ventricular vent is placed through the right superior pulmonary vein; a retrograde cardioplegia cannula is positioned within the coronary sinus, and the superior vena cava is encircled with a tape. If possible, an antegrade cardioplegia cannula is placed low in the ascending aorta. Perfusion cooling is initiated; and exposure of the ascending aorta, the arch, and the descending aorta is obtained (Fig 2). The inferior pulmonary ligament is divided. The fat pad containing the vagus and phrenic nerves is identified and protected. As soon as the heart fibrillates, the ascending aorta is clamped and antegrade cardioplegia is administered. If clamping of the aorta is not possible, only retrograde cardioplegia is used as soon as the ascending aorta is opened after circulatory arrest is established and every 20 minutes thereafter. While cooling is being effected, a long collagen-impregnated woven Dacron aortic graft (Hemashield; Meadox Medicals, Inc, Oakland, NJ) is selected, and a 10-mm graft (Hemashield; Meadox Medicals, Inc) is anastomosed to the aortic graft opposite the site of the planned anastomosis to the arch vessels with a continuous 40 polypropylene suture. When coronary bypass grafts are required, the distal anastomoses are performed during the period of cooling. Aortic valve replacement or reconstruction of the aortic root is also performed at this time, if indicated. Methylprednisolone $(7 \mathrm{mg} / \mathrm{kg}$ ) and thiopental (10 to 15 $\mathrm{mg} / \mathrm{kg}$ ) are given during cooling. Cooling is continued until electroencephalographic silence is achieved, usually at a nasopharyngeal temperature of $15^{\circ} \mathrm{C}$ to $17^{\circ} \mathrm{C}$. Ice packs are placed around the patient's head; the head is placed in a 


\begin{tabular}{|c|c|c|c|c|}
\hline Extent of lesion & Procedure & $\begin{array}{l}\text { Ventilatory } \\
\text { support }\end{array}$ & $\begin{array}{c}\text { Major } \\
\text { complications }\end{array}$ & Outcome \\
\hline Arch, proximal 2/3 DTA & $\begin{array}{l}\text { Replacement of diseased } \\
\text { segments, CABG }\end{array}$ & 1 day & $\begin{array}{l}\text { Transient postoperative } \\
\text { neurologic deficit }\end{array}$ & Alive and well \\
\hline Distal AA, arch, proximal 2/3 DTA & Replacement of diseased segments & 2 days & None & Alive and well \\
\hline Distal AA, arch, proximal 2/3 DTA & Replacement of diseased segments & 2 days & None & Alive and well \\
\hline Entire AA, arch, proximal 2/3 DTA & Replacement of diseased segments & 1 day & None & Alive and well \\
\hline $\begin{array}{l}\text { Distal AA, arch, entire } \\
\text { thoracoabdominal aorta }\end{array}$ & $\begin{array}{l}\text { AVR, CABG, replacement } \\
\text { of entire thoracic aorta }\end{array}$ & 15 days & $\begin{array}{l}\text { Temporary left vocal cord } \\
\text { paralysis; tracheostomy }\end{array}$ & Alive and well \\
\hline Arch, entire thoracoabdominal aorta & $\begin{array}{l}\text { Replacement of arch and } \\
\text { entire thoracic aorta }\end{array}$ & 1 day & None & Alive and well \\
\hline
\end{tabular}

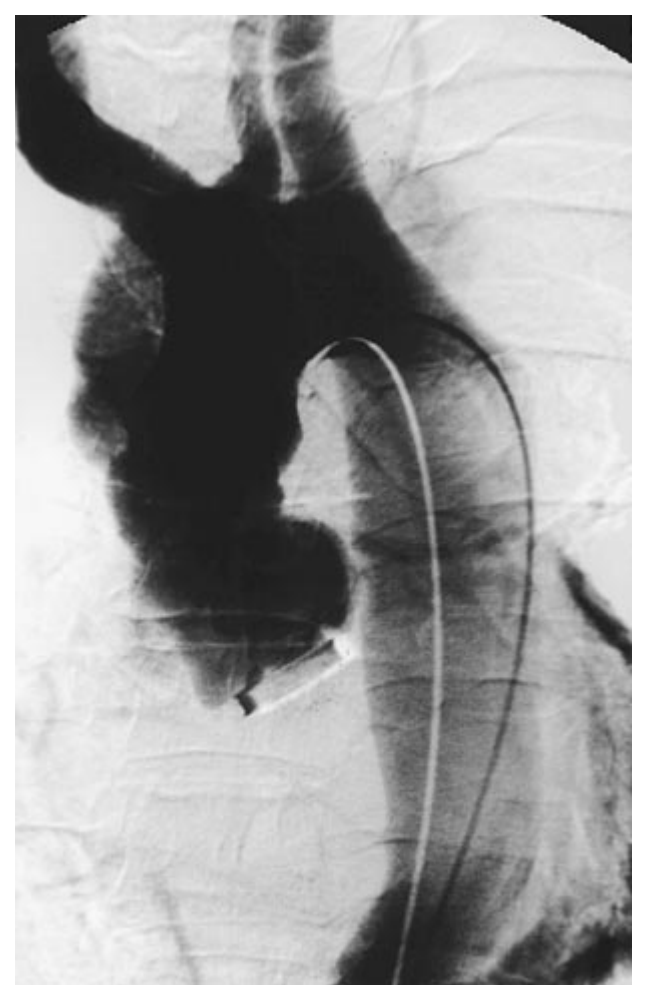

Fig 1. Preoperative aortogram from patient 3.

dependent position; the tape around the superior vena caval cannula is secured; the cannula is clamped; the intracardiac vent is occluded, and 1000 to $1500 \mathrm{~mL}$ of blood is drained into the venous reservoir.

With the circulation arrested, an aortic clamp is placed on the distal descending thoracic aorta to minimize blood loss into the operative field. The ascending aorta is incised, and a cuff of aortic tissue containing the arch vessels is prepared (Fig 3). The descending aorta is incised distal to the arch, and the previously prepared graft is passed down through the

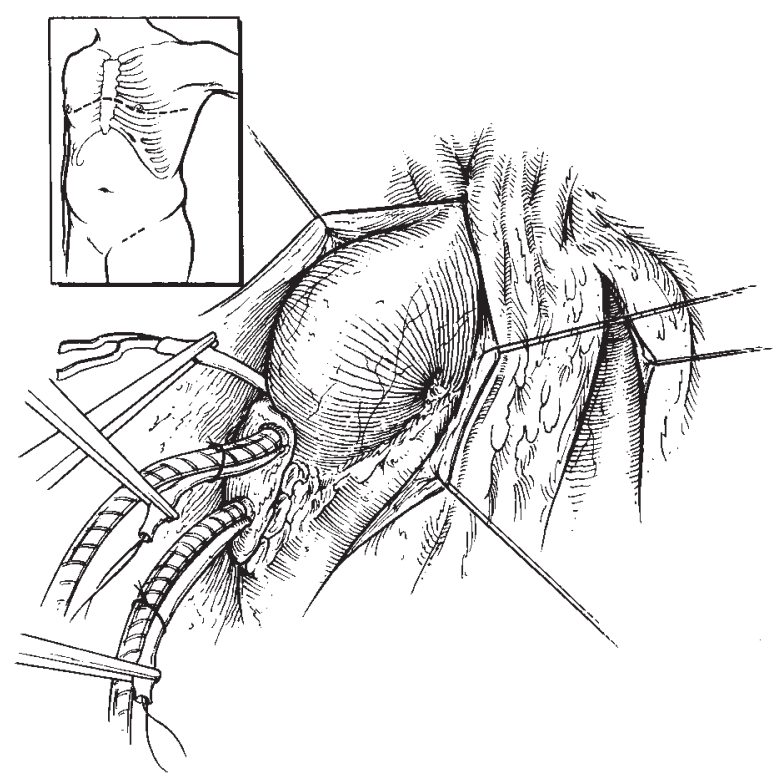

Fig 2. Patient positioning, incision, exposure of the mediastinal structures, and cannulation.

opening under the pedicle containing the vagus and phrenic nerves (Fig 4). An opening is made on the graft opposite the site of insertion of the $10-\mathrm{mm}$ graft, and the anastomosis to the arch vessels is performed (Fig 4). All aortic anastomoses are constructed with continuous 3-0 or 4-0 polypropylene suture, buttressed with a strip of Teflon felt. Graft-to-graft anastomoses are not buttressed. As the anastomosis to the brachiocephalic arteries is being completed, cold retrograde brain perfusion through the superior vena caval cannula is initiated at a flow of 600 to $900 \mathrm{~mL} / \mathrm{min}$, maintaining a central venous pressure of less than $30 \mathrm{~mm} \mathrm{Hg} .{ }^{11}$ The aortic graft is clamped just distal to the arch anastomosis with a straight clamp (Atraumax G-5030; Applied Medical, Laguna Hills, Calif) fitted with 61-mm inserts (G-6150; Applied 


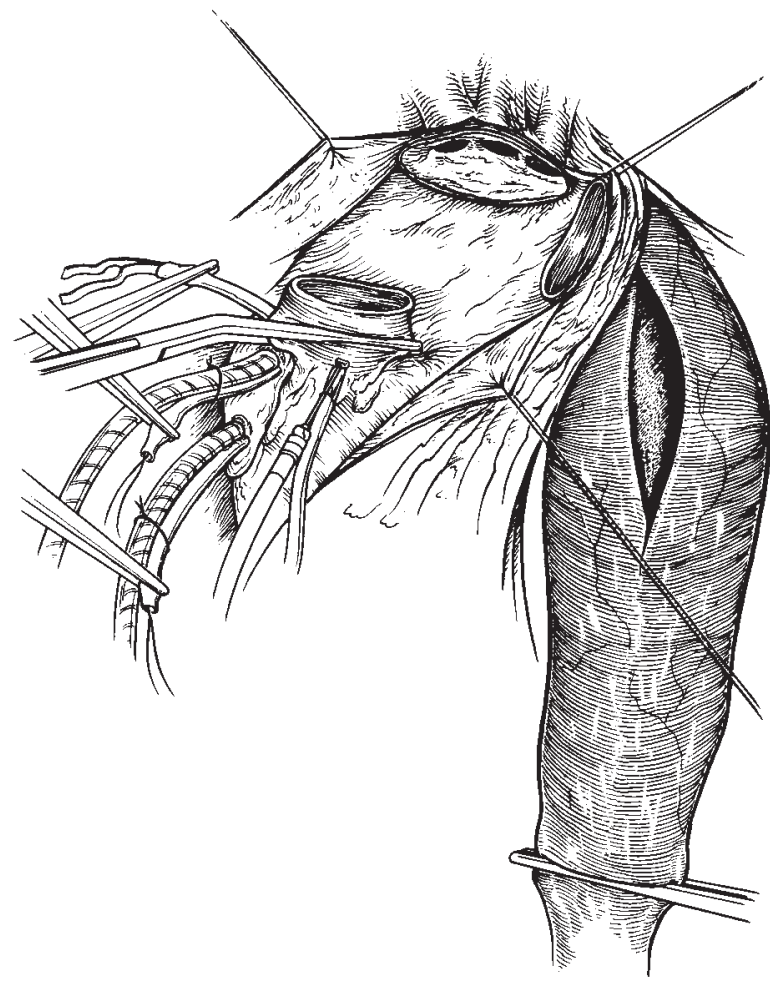

Fig 3. Circulatory arrest, exposure of the aorta, and resection of the aneurysm.



Fig 4. Anastomosis to the arch vessels.

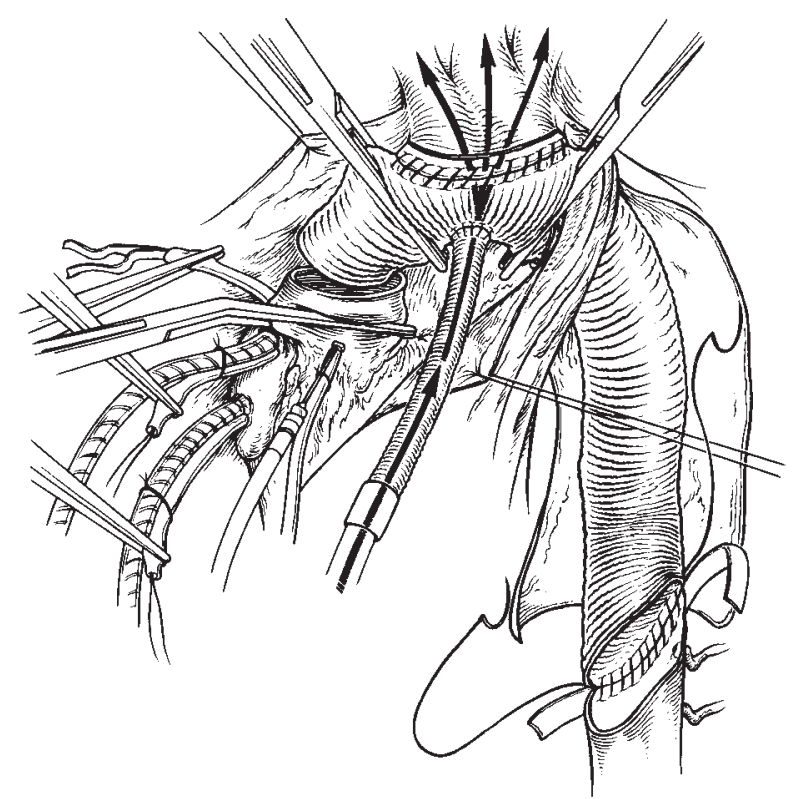

Fig 5. Antegrade cold arch perfusion; distal aortic anastomosis.

Medical). The second arterial line from the pump-oxygenator is attached to the $10-\mathrm{mm}$ graft, and antegrade arterial perfusion is established to evacuate air from the open, proximal part of the graft. Retrograde head perfusion is discontinued, and the aortic graft is clamped proximal to the aortic arch with a large angled clamp (CV 5050; V Mueller ZA) fitted with 86-mm inserts (G-8650; Applied Medical). Antegrade head perfusion then is established at 800 to $1200 \mathrm{~mL} / \mathrm{min}$ at a temperature of $20^{\circ} \mathrm{C}$ (Fig 5), and the superior vena caval occlusion clamp or tape and the clamp on the inferior vena cava are removed.

During the interval of hypothermic flow to the upper body, the distal clamp on the aorta is removed, and the graft is cut to the appropriate length. The distal aortic anastomosis is then performed with an open technique (Fig 5). The graft is beveled posteriorly, when possible, to preserve the origins of the lower intercostal arteries. In the presence of chronic dissection, the septum between the true and the false lumina is identified, and a large segment is removed to permit perfusion of both lumina. As this anastomosis is being completed, perfusion through the femoral arterial line is initiated to remove air and debris, and a small angled clamp (Atraumax G-5045, 61-mm inserts; Applied Medical) is placed on the graft to test the integrity of the anastomosis. The lower clamp on the aortic graft is removed, and the graft is deaired via several puncture holes opened with a 21-gauge needle. Perfusion via the femoral arterial cannula is discontinued; the distal arch clamp is removed, and flow is established in an antegrade direction via the $10-\mathrm{mm}$ graft, increasing flow to allow perfusion of the lower body (Fig 6). Rewarming is commenced at this time. Alternatively, if the distal anastomosis is technically difficult, it can be constructed with a separate 


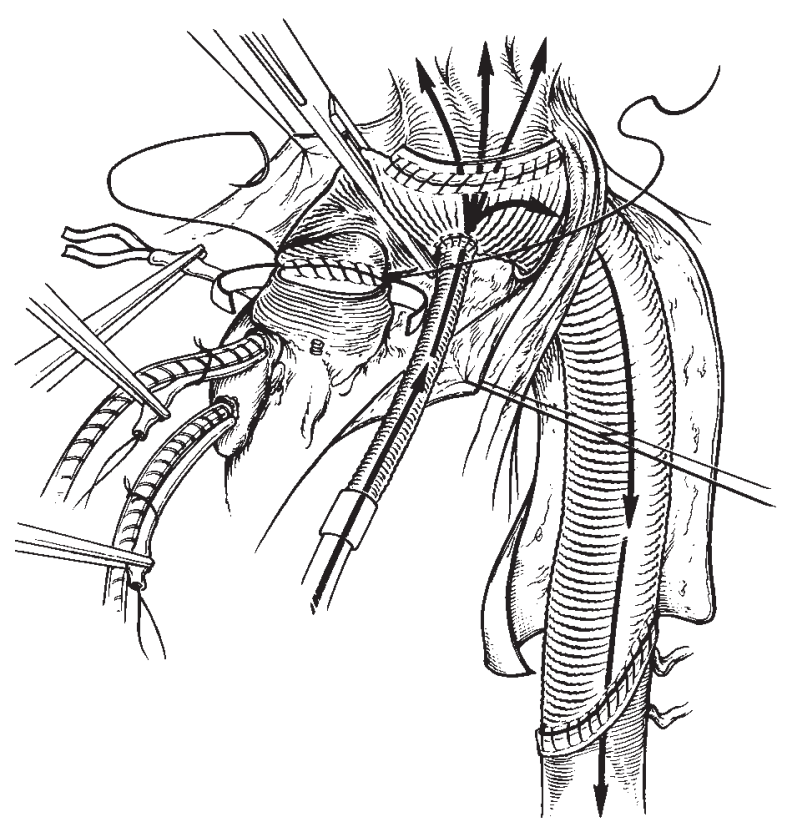

Fig 6. Antegrade perfusion and rewarming; proximal aortic anastomosis.

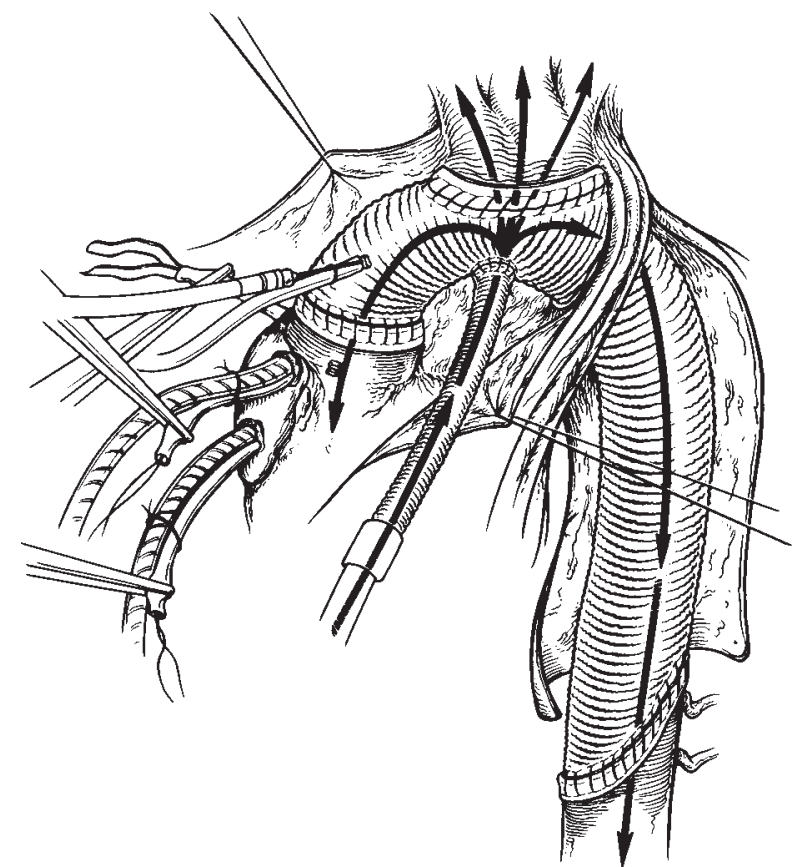

Fig 7. All clamps removed; weaning from cardiopulmonary bypass.

Table II. Perfusion data (in minutes)

\begin{tabular}{lcccccccc}
\hline Patient & $\begin{array}{c}\text { Circulatory } \\
\text { arrest* }\end{array}$ & $\begin{array}{c}\text { Retrograde } \\
\text { brain perfusion }\end{array}$ & $\begin{array}{c}\text { Arch } \\
\text { perfusion }\end{array}$ & $\begin{array}{c}\text { Lower body } \\
\text { ischemia }\end{array}$ & Cooling & Rewarming & $\begin{array}{c}\text { Myocardial } \\
\text { ischemia }\end{array}$ & $\begin{array}{c}\text { Total } \\
\text { CPB }\end{array}$ \\
\hline 1 & 34 & 7 & 27 & 61 & 50 & 56 & 137 & 159 \\
2 & 38 & 11 & 36 & 74 & 50 & 60 & 164 & 184 \\
3 & 46 & 11 & 23 & 69 & 46 & 63 & 164 & 162 \\
4 & 26 & 5 & 20 & 46 & 30 & 55 & 122 & 115 \\
5 & 44 & 9 & 36 & 80 & 35 & 80 & 218 & 248 \\
6 & 40 & 6 & 29 & 69 & 39 & 48 & 121 & 155 \\
Mean & 38 & 8 & 28 & 66 & 41 & 60 & 154 & 170 \\
\hline
\end{tabular}

$C P B$, Cardiopulmonary bypass.

*Includes duration of retrograde brain perfusion.

piece of graft, which is then sutured to the upper aortic graft in an end-to-end fashion (patients 5 and 6). After reperfusion of the lower body is established, the upper intercostal and bronchial arteries are ligated.

The proximal end of the aortic graft is sutured end to end to the proximal ascending aorta or the existing ascending aortic graft (Fig 6). The saphenous vein bypass grafts are anastomosed to the aortic graft at this time. Routine maneuvers to deair the heart are completed. A needle vent is placed on the proximal portion of the graft and connected to suction; the clamp proximal to the arch is removed (Fig 7). Hemostasis is effected, and the patient is weaned from cardiopulmonary bypass. The 10-mm graft is divided and is suture ligated close to the aortic graft. Two thoracostomy tubes are placed in each pleural space.

\section{Results}

There were no hospital deaths. Five patients were extubated within 48 hours of operation. Postoperative pneumonia developed that required temporary tracheostomy and assisted ventilation for 2 weeks in patient 5, who had pre-existing chronic obstructive pulmonary disease and a large aneurysm that involved the entire thoracic aorta. This patient also experienced the development of transient left vocal cord paralysis. One patient had a delayed postoperative neurologic deficit consisting of left hemiparesis from which he recovered completely. The perioperative mean transfusion requirement was 5.6 units of packed red cells (range, 49 units). All patients received fresh frozen plasma and 
platelet concentrates. None received cryoprecipitate. Aprotinin was not used. None of the patients had evidence for spinal cord ischemic injury. Renal function was preserved in all patients without the elevation of the serum creatinine level above baseline levels. There were no wound-related complications. One patient required re-exploration for the evacuation of a retained intrapleural clot. The mean duration of postoperative hospital stay was 15 days (range, 8-36 days). All patients are alive and well 2 to 26 months after the operation (mean follow-up, 9.5 months).

Perfusion data are summarized in Table II. The mean duration of circulatory arrest was 38 minutes (range, 34-46 minutes). Selective cold perfusion of the brachiocephalic vessels averaged 28 minutes (range, 20-36 minutes). The sum of these 2 periods represents the duration of lower body ischemia, which could be considered synonymous with the duration of spinal cord ischemia. This interval ranged from 46 to 80 minutes (mean, 66 minutes).

\section{Discussion}

Replacement of the thoracic aorta in stages may not be feasible when extensive aneurysmal disease in the arch makes staging technically challenging or when the presence of symptoms may be related to more than one diseased aortic segment. Single-stage replacement of the thoracic aorta with a bilateral anterior thoracotomy "clamshell" incision has been previously used with an operative risk comparable with that of the 2-stage approach. ${ }^{6,7}$ This incision provides an excellent exposure facilitating control of the distal aorta and the intercostal arteries. ${ }^{5}$

We believe the clamshell incision is particularly advantageous in reoperative procedures because it permits easier access to the mediastinal structures. Bicaval cannulation eliminates the need for central pulmonary artery cannulation and makes the administration of retrograde brain perfusion possible without the use of separate percutaneous catheters. ${ }^{12}$ Furthermore, it allows clear exposure of the phrenic and recurrent laryngeal nerves, reducing the possibility of injury.

Previously described techniques for single-stage replacement of the thoracic aorta involve a period of circulatory arrest during which the distal aortic and the arch anastomoses ${ }^{6,7}$ or the arch and the proximal aortic anastomoses ${ }^{12}$ are performed. A technique of hypothermic selective antegrade cerebral perfusion has been described by Ergin and associates. ${ }^{13}$ This technique involves perfusion of the head vessels via a separate graft that is later anastomosed to the aortic graft. Our technique reduces the duration of circulatory arrest by constructing the anastomosis to the arch vessel first and immediately reestablishing antegrade brain perfusion without further interruptions in cerebral blood flow. Furthermore, there is no need for separate cannulation of the head vessels. ${ }^{14}$ After retrograde head perfusion to evacuate particulate debris and air from the arch vessels, antegrade perfusion is established until cardiopulmonary bypass is discontinued. This should minimize the risk of retrograde atheroembolism.

Our technique does not allow adequate exposure of the infradiaphragmatic aorta. None of our patients required resection of this segment of the aorta. When indicated, the infradiaphragmatic aorta could be replaced either concurrently via a separate thoracoabdominal or abdominal incision or at a later time. We do not advocate the routine use of this technique for acute type A aortic dissection, unless extensive aortic replacement beyond the arch is planned.

The "arch-first" technique allows single-stage extensive replacement of the thoracic aorta to be performed with the shortest interval of circulatory arrest and minimizes the duration of retrograde aortic perfusion. Our initial experience justifies further clinical evaluation of this technique.

\section{Addendum}

Since submission of the manuscript, the technique has been used in 4 additional patients with large aneurysms (1) and chronic type A dissections (3). Patient 7 underwent composite graft replacement of the aortic root and replacement of the ascending aorta, aortic arch, and most of the descending aorta. After an uneventful initially postoperative course, he had a sudden cardiac arrest and died on postoperative day 4. Autopsy findings were unremarkable. Patients 8,9 , and 10 recovered uneventfully.

\section{REFERENCES}

1. Crawford E, Stowe C, Crawford J, Titus J, Weilbaecher D. Aortic arch aneurysm: a sentinel of extensive aortic disease requiring subtotal and total aortic replacement. Ann Surg 1984; 199:742-52.

2. Heinemann M, Laas J, Karck M, Borst HG. Thoracic aortic aneurysms after acute type A aortic dissection: necessity for follow-up. Ann Thorac Surg 1990;49:580-4.

3. Borst HG, Frank G. Treatment of extensive aortic aneurysms by a new multiple-stage approach. J Thorac Cardiovasc Surg 1988; 95:11-3.

4. Crawford E, Crawford J, Stowe C, Safi H. Total aortic replacement for chronic aortic dissection occurring in patients with and without Marfan's syndrome. Ann Surg 1984;199:358-62.

5. Massimo CG, Presenti LF, Marranci P, et al. Extended and total aortic resection in the surgical treatment of acute type A aortic dissection: experience with 54 patients. Ann Thorac Surg 1988; 46:420-4.

6. Minale C, Splittgerber FH, Reifschneider HJ. Replacement of the 
entire thoracic aorta in a single stage. Ann Thorac Surg 1994; 57:850-5

7. Cooley D. Surgical treatment of aortic aneurysms. Philadelphia: Saunders; 1986. p. 58-9.

8. Griepp RB, Stinson E, Hollingsworth JF, Buehler DB. Prosthetic replacement of the aortic arch. J Thorac Cardiovasc Surg 1975; 70:1051-63.

9. Svensson LG, Crawford ES, Hess KR, et al. Deep hypothermia and circulatory arrest: determinants of stroke and early mortality in 656 patients. J Thorac Cardiovasc Surg 1993;106:19-31.

10. Ergin MA, Galla JD, Lansman SL, Quintanta C, Bodian C, Griepp RB. Hypothermic circulatory arrest in operations on the thoracic aorta: determinants of operative mortality and neurologic outcome. J Thorac Cardiovasc Surg 1994;107:788-99.
11. Kouchoukos NT. Adjuncts to reduce the incidence of embolic brain injury during operations on the aortic arch. Ann Thorac Surg 1994;57:243-5.

12. Westaby S, Katsumata T. Proximal aortic perfusion for complex arch and descending aortic disease. J Thorac Cardiovasc Surg 1998;115:162-7.

13. Ergin MA, Griepp EB, Lansman SL, Galla JD, Levy M, Griepp RB. Hypothermic circulatory arrest and other methods of cerebral protection during operations on the thoracic aorta. J Card Surg 1994;9:525-37.

14. Bachet J, Guilmet D, Goudot B, et al. Cold cerebroblegia: a new technique of cerebral protection during operations on the transverse aortic arch. J Thorac Cardiovasc Surg 1991;102:8594.

\section{Timely}

The Journal of Thoracic and Cardiovascular Surgery delivers the information you need now. Articles usually appear within four months of acceptance. 